\title{
Promoting social distancing in a pandemic: Beyond the good intentions*
}

\author{
Paolo Falco ${ }^{\dagger}$ Sarah Zaccagni ${ }^{\ddagger}$
}

December 15, 2020

\begin{abstract}
Do reminders to promote social distancing achieve the desired effects? Much of the existing literature analyses impacts on people's intentions to comply. We run a randomised controlled trial in Denmark to test different versions of a reminder to stay home at the beginning of the crisis. Using a two-stage design, we follow up with recipients and analyse their subsequent behaviour. We find that the reminder increases ex-ante intentions to comply when it emphasises the consequences of non-compliance for the subjects themselves and their families, while it has no effect when the emphasis is on other people or the country as a whole. We also find, however, that impacts on intentions do not translate into equivalent impacts on actions. This is despite the possibility that respondents may tend to over-report compliance. Only people in poor health react to the reminder by staying home more. Our results shed light on important gaps between people's intentions and their actions in responding to the recommendations of health authorities.
\end{abstract}

JEL classification: C93, D90, D91, I12.

Keywords: COVID-19, social distancing, reminders, messaging, framing, experiment.

\footnotetext{
${ }^{*}$ We are grateful to Marco Piovesan, Claus Thustrup Kreiner, Rudi G.J. Westendorp, Laust Hvast Mortensen, Alexander Sebald, Davide Dragone, Pol Campos-Mercade, Christina Gravert, Mauro Caselli, Stefano Caria, Magnus Johansson, and all participants in the University of Copenhagen COVID-19 Seminar for their helpful comments. We are indebted to Bo Lønberg Bilde and his colleagues from DST Survey (Statistics Denmark) for their invaluable assistance and great efforts. We thank the Department of Economics, the Center for Economic Behaviour and Inequality (CEBI), the Department of Public Health ("CHALLENGE" project NNF17OC0027812), and the Centre for Healthy Ageing (CEHA) at the University of Copenhagen for their financial support. The activities of CEBI are funded by the Danish National Research Foundation. We are thankful to Arash Bal, Gan Khoon Lay, Nikita Kozin, and Priyanka from the Noun Project for some of the graphics used in our charts. All errors are our own.

${ }^{\dagger}$ Dept. of Economics, University of Copenhagen, E-mail: paolo.falco@econ.ku.dk (Corresponding author)

${ }^{\ddagger}$ Dept. of Economics and Center for Economic Behaviour and Inequality, University of Copenhagen, E-mail: sarah.zaccagni@econ.ku.dk
} 


\section{Introduction}

In the first months of 2020, a new type of coronavirus named SARS-CoV-2 began to spread like wildfire from China to the rest of the world. By the end of November, more than 63 million people had been infected and over 1,4 million people had died from the disease worldwide. $^{1}$

In the absence of a cure or a vaccine, fighting a pandemic requires people to abide by certain norms of behaviour (Van Bavel, Baicker, Boggio, Capraro, Cichocka, Cikara, Crockett, Crum, Douglas, Druckman, et al. [2020]) and to follow the guidelines of authorities in a coordinated fashion (Betsch, Böhm, and Korn [2013], Muscillo and Pin [2020]). Such recommendations span several domains, from personal hygiene to spending more time at home and avoiding contact with people who face the greatest risks (Markel, Stern, and Cetron [2008], Chen, Yang, Yang, Wang, and Bärnighausen [2020]).

Social distancing - the practice of maintaining a physical distance between people and reducing the number of times people come into close contact with each other - is the most effective way of reducing contagion (Glass, Glass, Beyeler, and Min [2006], Cetron, Maloney, Koppaka, and Simone [2004], Ferguson, Laydon, Nedjati Gilani, Imai, Ainslie, Baguelin, Bhatia, Boonyasiri, Cucunuba Perez, Cuomo-Dannenburg, et al. [2020]). It is also difficult to enforce. In its most extreme form, social distancing implies that people should remain in their homes and avoid contact with others, unless strictly necessary. Such strict forms of distancing have been applied in countries like Italy and France. Milder forms of social distancing have been encouraged across the globe.

Since social distancing is disruptive for people's lives, authorities have been struggling to find ways of promoting it (Lunn, Timmons, Barjaková, Belton, Julienne, and Lavin [2020]). Awareness campaigns have been numerous in many countries and reminders of different sorts have been used, ranging from social media campaigns to SMSs like those sent by the Danish Police to every mobile user (March 22) ${ }^{2}$ or the British government to every UK resident (March 24) ${ }^{3}$. In other contexts, such as smoking cessation, medical adherence (Vervloet, Linn, van Weert, De Bakker, Bouvy, and Van Dijk [2012], Altmann and Traxler [2014], Milk-

\footnotetext{
${ }^{1}$ Source: Worldometers website [link].

${ }^{2}$ Source: The Local DK (March 24, 2020) [link].

${ }^{3}$ Source: UK Government website (March 24, 2020) [link].
} 
man, Beshears, Choi, Laibson, and Madrian [2013], Milkman, Beshears, Choi, Laibson, and Madrian [2011]), physical activity (Calzolari and Nardotto [2017]), seat belt usage (Austin, Sigurdsson, and Rubin [2006]), take-up of social benefits (Bhargava and Manoli [2015]), electricity consumption (Gilbert and Zivin [2014], Allcott and Rogers [2014]), and giving to charitable organizations (Huck and Rasul [2010], Sonntag and Zizzo [2015], Damgaard and Gravert [2018]), reminders have been shown to cause behavioural change (Armanasco, Miller, Fjeldsoe, and Marshall [2017]).

Do messaging campaigns to promote social distancing achieve the desired objective? While few studies have shown that reminders affect people's ex-ante intentions (Barari, Caria, Davola, Falco, Fetzer, Fiorin, Hensel, Ivchenko, Jachimowicz, King, et al. [2020], Everett, Colombatto, Chituc, Brady, and Crockett [2020], Utych and Fowler [2020], Jordan, Yoeli, and Rand [2020]), we know little about subsequent impacts. In light of the large literature documenting intention-to-action gaps and time inconsistency across a wide range of domains (Kristal and Whillans [2020], Saba, Vassallo, and Turrini [2000], Abel, Burger, Carranza, and Piraino [2017], Kothe, Sainsbury, Smith, and Mullan [2015], Schwerdtfeger, Schmitz, and Warken [2012], Chen, Ho, Leung, Wang, and Lam [2019], Rhodes and de Bruijn [2013]), discrepancies between intended behaviour and subsequent actions deserve investigation. To the authors' knowledge, this is the first paper to test the impacts of reminders to promote social distancing on both intended behaviour and subsequent actions.

We run a randomised controlled trial in Denmark to test different versions of a reminder to stay home at the beginning of the crisis. Using a two-stage design, we follow up with recipients and we can analyse subsequent impacts. We find that the reminder increases exante intentions to comply when it emphasises the consequences of non-compliance for the subjects themselves or their families, while it has no impact when the emphasis is on other people or the country as a whole. Our main finding, however, is that respondents largely do not follow through with their intentions, as the reminder has no significant impacts on subsequent behaviour. This is consistent with the existence of imporatnt intention-to-action gaps. While the behaviour we study is self-reported, this does not pose a threat to our conclusions, since potential mis-reporting would likely go in the direction of compliance being over-stated (Gollwitzer, Martel, Marshall, Höhs, and Bargh [2020]). Despite that, we find no impact of the reminder on behaviour, despite the effect on ex-ante intentions. 
This study contributes to the literature on the effectiveness of reminders in promoting healthy behaviours (Vervloet et al. [2012], Altmann and Traxler [2014], Milkman et al. [2013], Milkman et al. [2011], Calzolari and Nardotto [2017], and Austin et al. [2006]). In particular, we relate directly to recent studies that have found impacts of reminders on people's intentions to comply with regulations to curb the spread of COVID-19 (Barari et al. [2020], Everett et al. [2020], Utych and Fowler [2020], Jordan et al. [2020]). We complement that literature by showing that intentions to comply may fail to translate into equivalent behavioural change.

Our study is also of immediate policy relevance. By focusing on the decision to stay home, we test the effectiveness of a key recommendation provided by health authorities across the world. From the UK Prime Minister ${ }^{4}$, to the President of the United States ${ }^{5}$, to the Queen of Denmark ${ }^{6}$, the advice to stay home as much as possible has been ubiquitous during the COVID-19 pandemic. Yet, convincing people to follow this recommendation is difficult, since it implies major changes to their routine and can be perceived as a severe limitation of individual freedom. This study shed light on those challenges.

\section{Experimental Design}

We conduct a pre-registered randomised controlled trial with Danish residents aged 18-69.7 We expose different groups to different variations of a recommendation to "stay home as much as possible" and we test the impact of the treatment on both respondents' intentions to stay home the following day and on whether they report having stayed home. Our data, described below, closely track widely used mobility measures based on mobile-phone data, corroborating the reliability of the information on respondents' behaviour.

We test four alternative ways of framing the recommendation, extending previous research that investigates self-interested versus prosocial motives as drivers of compliance with health recommendations (Vietri, Li, Galvani, and Chapman [2012],Li, Taylor, Atkins, Chapman, and Galvani [2016], Betsch, Böhm, Korn, and Holtmann [2017], Campos-Mercade, Meier, Schneider, and Wengström [2020], Cucciniello, Pin, Imre, Porumbescu, and Melegaro

\footnotetext{
${ }^{4}$ Source: BBC (March 23, 2020) [link].

${ }^{5}$ Source: The Washington Times (March 31, 2020) [link].

${ }^{6}$ Source: The Local DK (March 18, 2020) [link].

${ }^{7}$ Registry number AEARCTR-0005582 [link].
} 
[2020]). The first frame ("you") focuses on the potential consequences of the subject's behaviour for himself/herself. The second frame ("family") focuses on the consequences for his/her family. The third frame ("others") focuses on the consequences for other people in general. The fourth frame ("country") focuses on the broader consequences for the country as a whole by emphasising the risk of overloading the health system. This approach builds on existing studies showing that emotional proximity (whether the person affected by one's decision is a stranger or a friend) is an important determinant of people's choices (Montinari and Rancan [2013], Vekaria, Brethel-Haurwitz, Cardinale, Stoycos, and Marsh [2017]).

For each of the four treatments we test two variations. The first one, in the loss domain, emphasises the risks of not complying with the recommendation (for the respondent, the family, others, and the country). The second, in the gain domain, emphasises the benefits of complying with the recommendation. 
Table 1: The framing of reminders

\begin{tabular}{|c|c|c|}
\hline FRAME & DOMAIN & REMINDER \\
\hline \multirow{4}{*}{ You } & Loss & "If you go outside and become infected, you may get very serious respira- \\
\hline & & tory problems. Stay home as much as possible." \\
\hline & Gain & "If you stay home, you protect yourself from the risk of gettin \\
\hline & & respiratory problems. Stay home as much as possible." \\
\hline \multirow[t]{3}{*}{ Family } & Loss & "Think of your loved ones. If you go outside and become infected, you may \\
\hline & & $\begin{array}{l}\text { infect them, and they may get very serious respiratory problems. Stay home } \\
\text { as much as possible." }\end{array}$ \\
\hline & Gain & $\begin{array}{l}\text { "Think of your loved ones. If you stay home, you protect them from the } \\
\text { risk of getting very serious respiratory problems. Stay home as much as } \\
\text { possible." }\end{array}$ \\
\hline \multirow[t]{2}{*}{ Others } & Loss & $\begin{array}{l}\text { "If you go outside and become infected, you may infect others, who may } \\
\text { get very serious respiratory problems. Stay home as much as possible." }\end{array}$ \\
\hline & Gain & $\begin{array}{l}\text { "If you stay home, you protect others from the risk of getting very serious } \\
\text { respiratory problems. Stay home as much as possible." }\end{array}$ \\
\hline \multirow[t]{2}{*}{ Country } & Loss & $\begin{array}{l}\text { "If you go outside and become infected, you may contribute to an overload- } \\
\text { ing of the Danish health care system. Stay home as much as possible." }\end{array}$ \\
\hline & Gain & $\begin{array}{l}\text { "If you stay home, you reduce the risk of an overloading of the Danish } \\
\text { health care system. Stay home as much as possible" }\end{array}$ \\
\hline Generic & & "Stay home as much as possible." \\
\hline
\end{tabular}

Notes: The table provides an overview of the reminders we sent. We tested four frames with a focus on "you", "family", "others", and "country", respectively. Approximately 6,000 subjects were assigned to each frame. They were equally split between two variants of the frame (loss versus gain domain). In addition, 3,000 subjects received a generic reminder with no framing and 3,000 subjects in the control group received no reminder.

This approach builds on insights from prospect theory (Kahneman and Tversky [2013]) and borrows from a vast literature that has tested framing effects in a number of contexts (Andersson, Holm, Tyran, and Wengström [2016], Rothman, Martino, Bedell, Detweiler, and Salovey [1999], Ferrer, Klein, Zajac, Land, and Ling [2012], Tom, Fox, Trepel, and Poldrack [2007]).

In addition to these four framed messages, we send a generic reminder to stay home as much as possible without any framing. This is akin to the simple appeals made by health authorities and politicians in televised speeches and social media campaigns. Finally, a con- 
trol group receives no reminder. Table 1 reports a summary of the treatments, including the text of the reminders. Each treatment appeared to the respondents as a text box with the message on a red background (see Appendix B).

\section{Data Collection and Summary}

The study covers the period between March 25 and April 7, 2020, a time when the first wave of the crisis was at its peak in Denmark and financial markets in turmoil, causing authorities to adopt stringent measures (including the closure of non-essential economic activities and of the borders), which however did not include an obligation to stay home as in other countries (e.g., Italy, France). Appendix G provides a detailed timeline of the initial phase of the crisis in Denmark and shows that our study falls within the most critical period.

The different reminders were randomised within a representative sample of 29,756 Danish residents between the age of 18 and 69 , who represent close to $1 \%$ of the population. Statistics Denmark (the national statistical office) carried out the randomisation and distributed the treatment via e-Boks - the official system of communication used by public authorities in Denmark, which is akin to a personal email account. ${ }^{8}$ Respondents received a message inviting them to participate in a survey to investigate people's habits at the time of the COVID-19 crisis. Those who agreed to participate landed on a dedicated webpage where they were first shown the reminder (if they were in one of the treated groups) and then answered eight questions (control subjects only saw the questions). Out of the 29,756 subjects contacted by Statistics Denmark, a total of 12,573 (42,2\%) completed the first survey. Out of those, 6,681 (22.3\%) completed the second survey. ${ }^{9}$ We drop 2 respondents whose answers to the questions on time spent home exceed 24 hours and 7 observations in which the follow-up refers to the day before the treatment occurred (which was the result of a technical problem). Furthermore, since some of the participants responded with some delay, it is possible that the answers to the follow-up questionnaire do not refer to the same day as the

\footnotetext{
${ }^{8}$ By focusing on the general population of Danish residents, we avoid having to rely on selected panels of respondents on dedicated survey platforms, who may have been solicited frequently during the COVID-19 crisis and may be subject to fatigue (Porter, Whitcomb, and Weitzer [2004], Goodman, Cryder, and Cheema [2013]).

${ }^{9}$ The first questionnaire was sent to respondents on March 25 and the last responses to the second questionnaire were received on April 7.
} 
answers to the first questionnaire. To prevent major inconsistencies, we drop from the analysis respondents whose answers to the first questionnaire referred to a weekday, while their answers to the follow-up questionnaire referred to a day of the weekend, and vice-versa. This makes our results more precise, but does not change them qualitatively (as discussed below). This leaves us with a balanced panel of 5,310 respondents, which we use for the analysis. Attrition is balanced across treatment groups and does not depend on the kind of reminder respondents receive (see Appendix $\mathrm{H}$ ). As a result, covariates are balanced across treatments (see Table 2 in Appendix A).

While the first questionnaire asked about intentions to stay home the day after, the second questionnaire asked about whether the respondent went out the day before (both questionnaires are available in Appendix C). Specifically, we asked respondents how long they were planning to spend (first questionnaire) or did spend (second questionnaire) outside their home, and we treated positive answers as instances of not staying home. ${ }^{10}$ Since the information on actions (i.e., whether a person stayed home) is self-reported by the respondent in our follow-up survey, we use the data released by Apple Inc. on mobility trends during the COVID-19 pandemic to validate the reliability of this measure. ${ }^{11}$ Apple publishes daily reports on mobility trends based on mobile phone data, in countries and cities around the world. We extract the data for Denmark and we compare them with the distance that the subjects declared to have travelled the day before in our follow-up survey. To make the two series comparable, we calculate percentage changes in mobility compared to the first day for which we have information in our dataset. The results are reported in Appendix G (Figure $5)$.

A summary of our data shows that less than $15 \%$ of respondents intend to stay home the next day during the most critical period of the first pandemic wave, and $42 \%$ of them do not follow the declared intentions and go out instead (Figure 1). Intentions to stay home are higher among women and lower-income households, while they do not change significantly by age or education levels. People with relatively poor health conditions are the most likely to stay home and the least likely to deviate from such an intention.

\footnotetext{
${ }^{10}$ We believe this is a preferable strategy to asking whether respondents were planning to go out (a "Yes/No" question), since it induced more careful reflection. The results are robust to treating respondents who only went out for a very short time (e.g., less than 5, 10, or 20 minutes) as having stayed home.

${ }^{11}$ Source: Mobility Trends Report by Apple Inc. [Link].
} 
Figure 1: The gap between intentions and actions

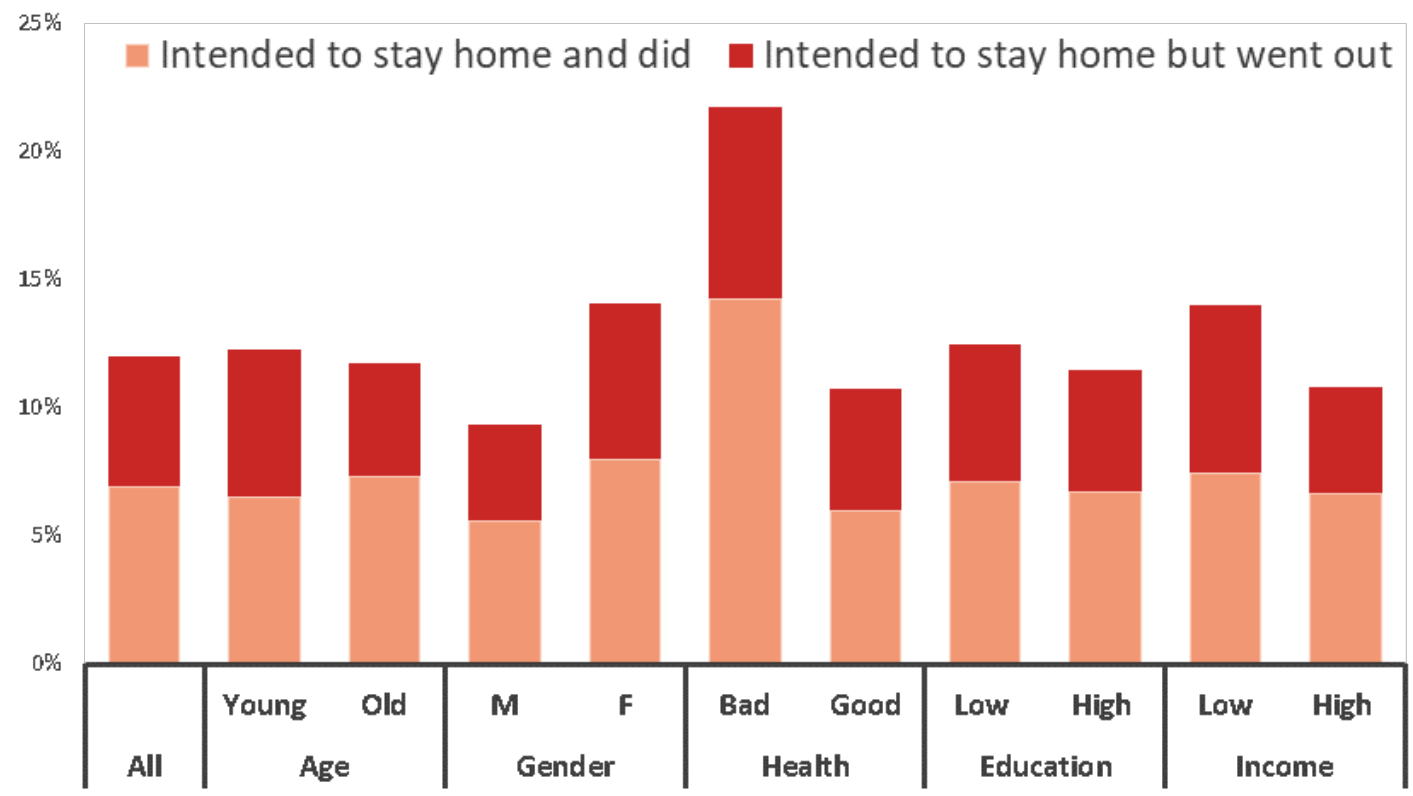

Notes: $42 \%$ of the respondents who intend to stay home do not follow their intentions and go out instead. Intentions to stay home are higher among women and lower-income households, while they do not change significantly by age or education levels. People with relatively poor health conditions are the most likely to stay home and the least likely to deviate from such an intention. The sample for this figure is restricted to respondents whose answers to the first and the second questionnaires refer to the same day, since we are interested in documenting inconsistencies $(\mathrm{N}=3,032)$. The subsequent analysis of treatment effects can rely on a larger sample since we do not need an exact match between the days. The different categories are defined as follows: young: < 50; low education: < post-secondary degrees; low income: household disposable income per capita $<250,000$ DKK (approx. 36,000 USD).

\section{Estimation Strategy}

To measure the effects of the reminders, we compare the probability of going out in each of our treatment groups with the probability of going out among respondents in the control group that received no treatment. More specifically, we estimate the following econometric model:

$$
Y_{i}=\beta_{0}+\beta_{1} T_{i, 1}+\beta_{2} T_{i, 2}+\beta_{3} T_{i, 3}+\beta_{4} T_{i, 4}+\beta_{5} T_{i, 5}+\gamma X_{i}+\epsilon_{i}
$$

where $Y_{i}$ is a dummy capturing whether the respondent stays home and equal to 1 when 
the respondent answers 0 to a question on the amount of time spent outside home. ${ }^{12}$ We estimate the same model twice, first on intended outcomes from the baseline survey and then on realised outcomes from the follow-up. $T_{1}-T_{5}$ are dummies equal to 1 if subject $i$ was randomly assigned to each of the 5 treatments $\left(T_{i, 1}=\right.$ You, $T_{i, 2}=$ Family, $T_{i, 3}=$ Others, $T_{i, 4}$ $=$ Country, $T_{5}=$ No framing / Generic), and, is the error term. The first four dummies are further split in two when we separate the gain from the loss domain $\left(T_{i, 1 L}=\right.$ You (Loss), $T_{i, 1 G}$ $=$ You (Gain), $T_{i, 2 L}=$ Family (Loss), $\ldots, T_{5}=$ No frame $/$ Generic).$X_{i}$ is a vector of covariates used at the randomisation stage to ensure balance between the groups. The variables included are gender, age, education, region, and household disposable income per capita. The control group is composed of people who do not receive any reminder. Hence, $\beta_{0}$ captures the proportion of people in the control group who intend to stay home (in the estimation on intentions) or actually do (in the estimation on subsequent actions). When we split the analysis by the health status of respondents, we divide the sample in two groups and estimate the model above separately on each of them.

\section{Results}

\subsection{Impacts on intentions and actions}

Our first finding is that the reminder significantly increases respondents' intentions to stay home when it is framed with respect to personal consequences and consequences for one's family. ${ }^{13}$ Figure 2 summarises the results, while Table 6 in Appendix D shows the full set of estimates. For simplicity, it reports them as percent increases relative to the share of people who stay home in the control group, which is just below 15\% (i.e., an effect of 20 percent amounts to a 3-percentage point increase in the share of people who stay home, or 3 people out of 100). With both the "you" and the "family" framing, the treatment effect amounts to an increase in the share of people who intend to stay home of about $46 \%$ ( $p=0.007$ and

\footnotetext{
${ }^{12}$ The question specifies that by "outside one's home" it means "outside one's property". Being in the home garden, for instance, should not be considered being out of one's home.

${ }^{13}$ We test the null hypothesis of no difference between the control and each treatment group using standard significance testing. To this end, we estimate the empirical model outlined in Section 4 . For ease of exposition, we report treatment effects as percentage changes relative to the control group, together with the corresponding $\mathrm{p}$-values and F-statistics.
} 
$\mathrm{p}=0.008$, respectively) compared to the control group. On the other hand, the reminders have insignificant effects on intentions to stay home when they are framed with respect to the consequences for other people in general $(12 \%$ with $p=0.459)$ and for the country as a whole $(26.6 \%$ with $\mathrm{p}=0.11)$. Similarly, the reminder with no framing - akin to the slogans commonly seen on social media (e.g., \# STAYHOME) and promoted by governments around the world (e.g., the SMS sent by the UK government and the Danish Police ${ }^{14}$ ) - has a statistically insignificant effect $(26 \%, \mathrm{p}=0.19)$. These findings are in line with the hypothesis that emotional proximity to the people affected by the respondent's actions plays a strong role in determining the success of a message. They are also consistent with the findings of an interesting recent literature that uses experimental methods to study pro-social behaviour as a driver of health behaviour, including social distancing (Muscillo and Pin [2020], Jordan et al. [2020], Campos-Mercade et al. [2020]). We complement those findings by showing that individuals who comply with social distancing to protect others may do so primarily to protect their family.

Our second result is that when we further break down the most effective treatments ("you" and "family") and look at the sub-treatments in the gain and loss domain separately, we find very similar impacts independently of the domain. The estimated treatment effect on intentions ranges from $42 \%(\mathrm{p}=0.044)$ for the "family" treatment in the gain domain to $49 \%$ ( $\mathrm{p}=0.017)$ for the "family" treatment in the loss domain. The other treatments ("others" and "country") have no statistically significant impacts on intentions neither in the gain nor in the loss domain. The full set of results is available in 6 in Appendix D.

Our third result is that changes in intentions do not translate into sizeable changes in actions. The two most effective treatments identified above ("you" and "family") - with effects on intentions of over $45 \%$ - only result into a $19.7 \%(\mathrm{p}=0.127)$ and a $14.9 \%(\mathrm{p}=$ 0.251 ) increase in the share of subjects who actually stay home relative to the control group. The other treatments, which had lower insignificant impacts on intentions have even lower impacts on actions ${ }^{15}$. When we test the joint hypothesis that all the reminders have an effect

\footnotetext{
${ }^{14}$ Source: The Local DK (March 24, 2020) [link]; UK Government website (March 24, 2020) [link].

${ }^{15}$ Since detecting the potential significance of lower effects on actions is statistically more difficult, we run some robustness checks by aggregating affine treatments (as detailed in Appendix E). Even then, we are unable to detect significant impacts on behaviour.
} 
on actions equal to zero, we cannot reject it $(\mathrm{F}(5,5299)=0.75, \mathrm{p}=0.589) .{ }^{16}$

Coupled with the first result, this evidence confirms that intention-to-action gaps can limit the effectiveness of messaging campaigns of this kind (Schwerdtfeger et al. [2012], Sniehotta, Scholz, and Schwarzer [2005]), a possibility that has received limited attention in the existing literature on the impact of reminders during the COVID-19 pandemic (Barari et al. [2020], Everett et al. [2020], Utych and Fowler [2020], Jordan et al. [2020], Blagov [2020]). 17 In Appendix E, we run a battery of robustness checks, which lend further support to our conclusions.

One concern with the results is that the size of our sample poses challenges for statistical power and makes it difficult to detect a statistically significant effect on actions. When assessing this possibility, it is important to remark that the effects we detect are small. Since compliance in the control group is below 15\%, an increase of approximately $20 \%$ in the probability of staying home corresponds to a change of less than 3 percentage points (or 3 people every 100). Detecting such a small impact would pose a statistical challange even with a larger sample, which was beyond our possibilities. On the other hand, it seems reasonable to argue that an effect of such magnitude would be considered of limited societal relevance by many policy-makers, even if estimated more precisely. Finally, our conclusions are robust to the possibility that respondents may over-report staying home due to experimenter demand effects (Gollwitzer et al. [2020]). Indeed, despite such potential over-reporting, we are unable to detect sizeable impacts on reported behaviour.

\footnotetext{
${ }^{16}$ We also cannot reject the joint hypothesis that all the sub-treatments (considering the loss and the gain domain separately) have no impact on actions $(F(9,5295)=0.75, \mathrm{p}=0.659)$.

${ }^{17}$ Such gaps may be due to systematic behavioural biases (e.g., time inconsistency) or idiosyncratic shocks forcing people to deviate from their intentions. While explaining such mechanisms is beyond the scope of this paper, documenting the divergence between intentions and actions is crucial for our understanding of how effective reminders are.
} 
Figure 2: The effects of different reminders on intentions and actions

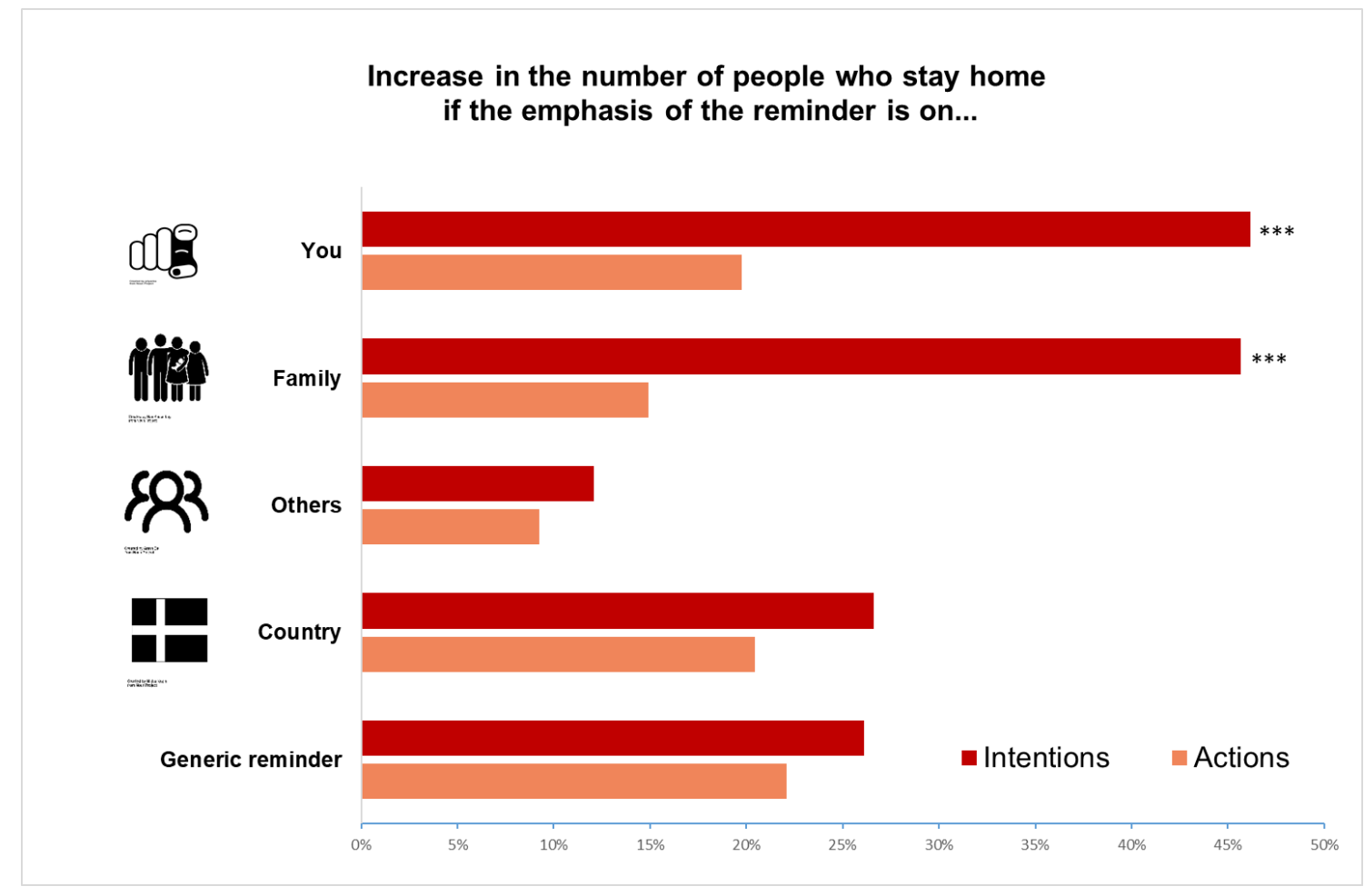

Notes: The effects are percentage changes relative to the share of people who intend to stay home or stayed home in the control group (i.e., the regression coefficients in Table 6 in Appendix D are divided by the share of people who intend to stay home (intentions) and stayed home (actions) in the control group). Intentions refer to the day after the first interview, actions refer to the day before the follow-up interview. The reminder increases respondents' intentions to stay home by $46 \%$ when it is framed with respect to personal consequences $(p=0.007)$ and consequences for one's family $(p=0.008)$. It has a lower insignificant effect on intentions when it refers to consequences for other people in general $(\mathrm{p}=$ $0.459)$, for the country as a whole $(p=0.110)$, and when it has no specific framing $(p=0.190)$. Changes in intentions do not translate into sizeable changes in actions. The reminders with a focus on personal consequences and consequences for one's family only increase the share of people who stay home by $19.7 \%(\mathrm{p}=0.127)$ and $14.9 \%(\mathrm{p}=0.251)$, respectively. As for intentions, the reminders have no significant impact on actions when they focus on "others" $(p=0.467)$, "country" $(p=0.113)$, or have no framing $(\mathrm{p}=0.15)$. Respondents who referred to a weekday in the first interview and to a weekend day in the follow-up interview (and vice-versa) are dropped from the sample to avoid inconsistencies. The resulting sample size is $N=5,310$. Stars reported at the top of the bars express the level of significance of the coefficient $\left.{ }^{* * *} \mathrm{p}<0.01,{ }^{* *} \mathrm{p}<0.05,{ }^{*} \mathrm{p}<0.1\right)$.

\subsection{Healthier people are harder to convince}

The effects of the reminders may vary across social groups and many would argue that, in order to increase their effectiveness, they should be targeted at those who are least likely to comply with the recommendation. Previous research, for instance, finds that people who face the lowest risks from being infected are the most likely to diverge from social distancing 
measures during the COVID-19 pandemic (Barari et al. [2020]). Are such groups responsive to the reminders? To answer this question, we split subjects according to their health status and repeat the analysis on separate samples. ${ }^{18}$ Figure 3 shows the results for the two most powerful treatments. Table 8 in Appendix F reports the full set of estimates. The results indicate that respondents who are in worse health conditions and face the greatest risks from an infection are the most affected by the treatments. Being reminded of the risks of going out for themselves and their families more than doubles their intended probability to stay home ( $\mathrm{p}=0.052$ and $\mathrm{p}=0.036$, respectively) and increases their probability of actually staying home by over $80 \%\left(p=0.067\right.$ and $p=0.034$, respectively) ${ }^{19}$ The strong effect of the "family" reminder among people in bad health may be due to the fact that it reminds them of the burden and suffering that a worsening of their health conditions would impose on their loved ones. Another plausible explanation is that subjects in poor health live with other people in similar health conditions (e.g., older couples).

On the other hand, people with better health, who face the lowest risks from an infection (and are the ones who go out of their homes the most) are less affected by the reminders. The share among them who declare an intention to stay home increases by $36.5 \%$ when the reminder is about personal risks and $38.2 \%$, when the reminder is about risks for others, but the effects are only significant at the $10 \%$ level ( $p=0.099$ and $p=0.089$, respectively). On the other hand, we are unable to reject the joint hypothesis that all the reminders have no effect on actions among people in good health $(F(9,4689)=0.70, p=0.711)$. These results show that reminders may help to protect groups at risk by increasing their likelihood of staying home, while they do not increase compliance among those who face limited personal health risks but may spread the disease.

\footnotetext{
${ }^{18}$ The lowest two (out of five) values of a variable indicating health status are considered bad health conditions for the purpose of this analysis (this is the categorisation that appears to be most sensible, since only considering in bad health those with the lowest value would leave us with a very small sample size).

${ }^{19}$ These effects are even stronger if we focus on people with poor health who are relatively old (50 and above). Not shown for conciseness.
} 


\section{Figure 3: Treatment effects of the most effective reminders by the health status of the recipient}

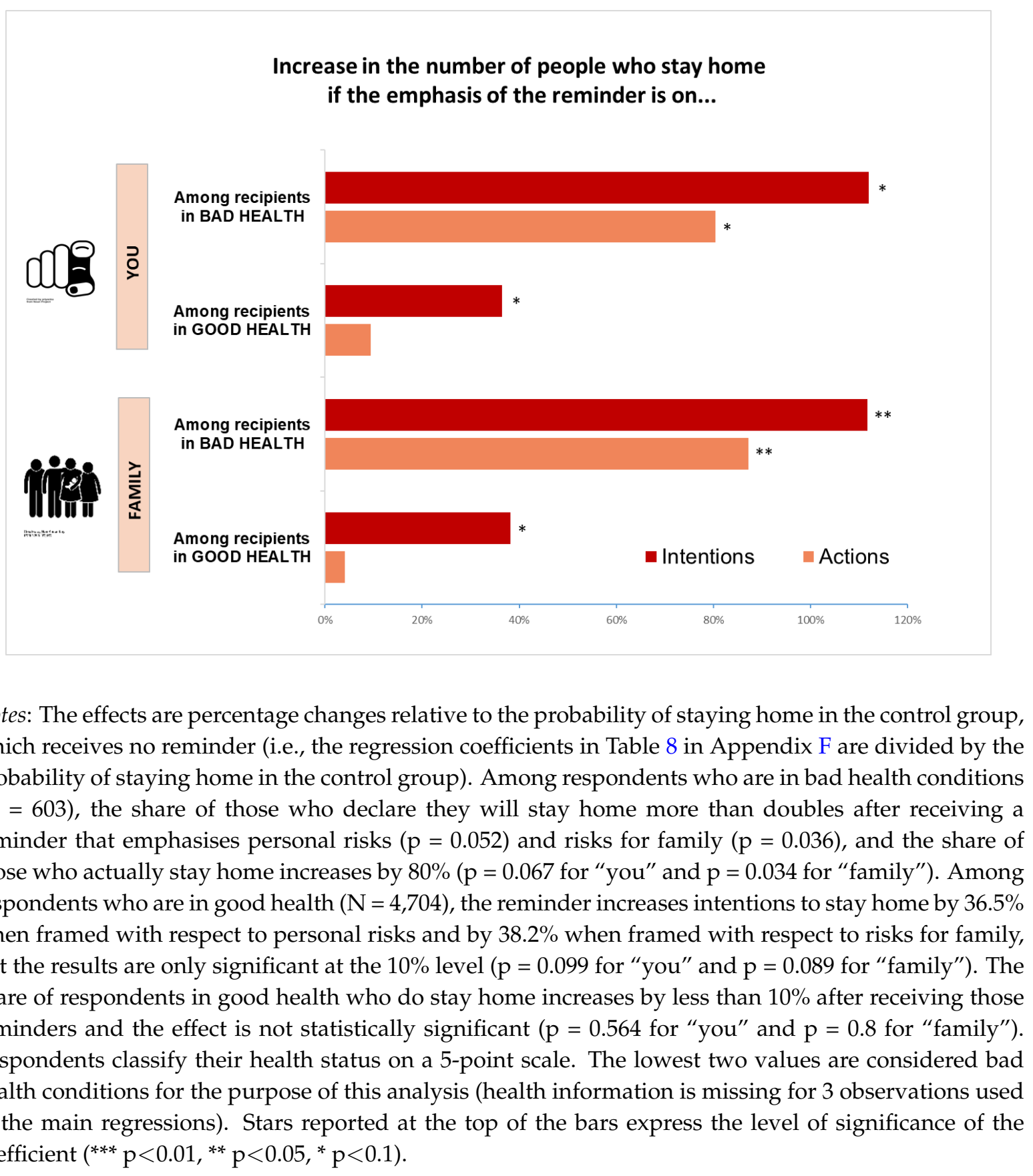

\subsection{Robustness Checks}

In this section, we document the results of a battery of robustness checks to test the sensitivity of our results with respect to some key choices made when defining the sample of interest. The results are reported in Table 7 in Appendix E.

First, the sample for the analysis was limited to respondents who referred to a weekday 
or a weekend day both in the baseline and in the follow-up survey (Col.1-2). This is a reasonable approach, as not doing so would make the two answers incomparable. Nonetheless, we check the robustness of our results to reinstating all the observations we have. Upon doing that, we find that the magnitude of the effects of the most effective treatments ("you" and "family") decreases slightly, but treated subjects still declare an intention to stay home $31 \% 20$ more than subjects in the control group (whose likelihood to stay home is 10.6\%). Column 2 confirms the fact that there are no significant effects on the actions as discussed above.

Second, we test how our results change when we drop respondents who declared an intention to spend (or having spent) 24 hours outside their home (Col.3-4). Such responses are genuinely difficult to interpret. Those people may be away from their home for several days and may well have isolated themselves where they are (e.g., at a vacation house, which would not seem unlikely at the time of the experiment given the good weather), despite having reported being away from home for the entire day. Whether we drop such observations or code them as if the respondents stayed home, our results do not change.

Third, certain respondents answer the follow-up questionnaire with a significant delay after having responded to the baseline survey (Col.5-6). This poses potential concerns regarding the comparability of their answer in the first questionnaire with their answers in the second one. When we confine the analysis to respondents who complete the follow-up questionnaire within one week from the baseline, both the magnitude and the statistical significance of the estimated treatment effects increase slightly for the most effective treatments ("you" and "family"), but our conclusions do not change.

Fourth, since the COVID-19 crisis evolved very quickly and the situation changed between the first and the second week in our study period (as the Danish government gave the first signs of wishing to relax the restrictions it had imposed), we also test how the results change when we separate subjects who responded within the first week from the rest (Col. 7-8). When we drop the latter (who responded at a time when the situation was starting to become less tense in Denmark), our conclusions do not change. In fact, the effect on intentions of the treatment framed with respect to the dangers for one's family becomes even stronger and remains statistically significant despite the lower sample size. We still do not detect, however, significant impacts on actions, except for a positive effect of the "you"

\footnotetext{
20 "Family" treatment in the loss domain.
} 
treatment in the gain domain, which is only significant at the $10 \%$ level.

Finally, since the treatment effects on actions appear to be generally smaller than those on intentions, detecting their statistical significance is naturally more difficult. In order to increase statistical power, we pool the "you" and the "family" treatment and re-run the analysis on both intentions and actions. Such a strategy is inspired by the conceptual affinity of those two treatments (both pertaining to the personal sphere) and is corroborated by the fact that they have very similar effects on both intentions and actions throughout the analysis. For simplicity, we also pool the other two framed treatments ("others" and "country"), which are also conceptually affine (whether we do that or not, however, does not change the results). Upon running such a test (Col.9-10), we are unable to detect significant effects of the aggregate treatments on actions, despite the increase in statistical power, and our conclusions do not change.

\section{Discussion}

This paper sheds new light on the effectiveness of messaging campaigns in promoting social distancing during the COVID-19 pandemic. It reveals that while reminders may be effective in changing people's intentions, those intentions are not matched by sizeable changes in subsequent actions. The conclusion is robust to the possibility that respondents may overreport compliance. If anything, that should artificially inflate our estimate impacts. Despite that, the effects we detect are small and statistically insignificant.

Our evidence indicates that intention-to-action gaps may be an important obstacle in the promotion of social distancing during a pandemic and that messaging campaigns are unlikely to be effective unless they tackle such gaps. This could be achieved, for instance, by increasing the frequency of reminders to reduce the burden of time inconsistency, though the benefits of such a strategy should be weighed against the risk of habituation. We also show that reminders are most effective in inducing behavioural change among people in relatively poor health, while subjects who are in good health are not affected. This is consistent with the idea that reminders are meant to leverage people's prior convictions, rather than changing people's minds. This suggests that in order to induce behavioural change, reminders should be targeted at specific audiences. 
Our findings bear important lessons for the international community. Messaging campaigns like the one we tested have been used extensively across the world and will continue to play an important role for the foreseeable future. Understanding what types of messages are most effective and being alert to the existence of important gaps between people's intentions and their actions will help to inform more effective messaging campaigns. 


\section{References}

M. Abel, R. Burger, E. Carranza, and P. Piraino. Bridging the intention-behavior gap? the effect of plan-making prompts on job search and employment. The World Bank, 2017.

H. Allcott and T. Rogers. The short-run and long-run effects of behavioral interventions: Experimental evidence from energy conservation. American Economic Review, 104(10):3003$37,2014$.

S. Altmann and C. Traxler. Nudges at the dentist. European Economic Review, 72:19-38, 2014.

O. Andersson, H. J. Holm, J.-R. Tyran, and E. Wengström. Deciding for others reduces loss aversion. Management Science, 62(1):29-36, 2016.

A. A. Armanasco, Y. D. Miller, B. S. Fjeldsoe, and A. L. Marshall. Preventive health behavior change text message interventions: a meta-analysis. American Journal of Preventive Medicine, 52(3):391-402, 2017.

J. Austin, S. O. Sigurdsson, and Y. S. Rubin. An examination of the effects of delayed versus immediate prompts on safety belt use. Environment and behavior, 38(1):140-149, 2006.

S. Barari, S. Caria, A. Davola, P. Falco, T. Fetzer, S. Fiorin, L. Hensel, A. Ivchenko, J. Jachimowicz, G. King, et al. Evaluating covid-19 public health messaging in italy: Self-reported compliance and growing mental health concerns. medRxiv, 2020.

C. Betsch, R. Böhm, and L. Korn. Inviting free-riders or appealing to prosocial behavior? game-theoretical reflections on communicating herd immunity in vaccine advocacy. Health Psychology, 32(9):978, 2013.

C. Betsch, R. Böhm, L. Korn, and C. Holtmann. On the benefits of explaining herd immunity in vaccine advocacy. Nature human behaviour, 1(3):1-6, 2017.

S. Bhargava and D. Manoli. Psychological frictions and the incomplete take-up of social benefits: Evidence from an irs field experiment. American Economic Review, 105(11):3489_ $3529,2015$. 
P. S. Blagov. Adaptive and dark personality traits in the covid-19 pandemic: Predicting health-behavior endorsement and the appeal of public-health messages. PsyArXiv Preprints, 10, 2020.

G. Calzolari and M. Nardotto. Effective reminders. Management Science, 63(9):2915-2932, 2017.

P. Campos-Mercade, A. Meier, F. Schneider, and E. Wengström. Prosociality predicts health behaviors during the covid-19 pandemic. University of Zurich, Department of Economics, Working Paper, (346), 2020.

M. Cetron, S. Maloney, R. Koppaka, and P. Simone. Isolation and quarantine: containment strategies for sars 2003. Learn from SARS Prep Next Dis Outbreak Work Summ, pages 71-83, 2004.

J. Chen, S. Y. Ho, L. T. Leung, M. P. Wang, and T. H. Lam. School-level electronic cigarette use prevalence and student-level tobacco use intention and behaviours. Scientific reports, 9(1):1-7, 2019.

S. Chen, J. Yang, W. Yang, C. Wang, and T. Bärnighausen. Covid-19 control in china during mass population movements at new year. The Lancet, 395(10226):764-766, 2020.

M. Cucciniello, P. Pin, B. Imre, G. Porumbescu, and A. Melegaro. Altruism and vaccination intentions: Evidence from behavioral experiments. medRxiv, 2020.

M. T. Damgaard and C. Gravert. The hidden costs of nudging: Experimental evidence from reminders in fundraising. Journal of Public Economics, 157:15-26, 2018.

J. A. Everett, C. Colombatto, V. Chituc, W. J. Brady, and M. Crockett. The effectiveness of moral messages on public health behavioral intentions during the covid-19 pandemic. 2020.

N. Ferguson, D. Laydon, G. Nedjati Gilani, N. Imai, K. Ainslie, M. Baguelin, S. Bhatia, A. Boonyasiri, Z. Cucunuba Perez, G. Cuomo-Dannenburg, et al. Report 9: Impact of non-pharmaceutical interventions (npis) to reduce covid19 mortality and healthcare demand. 2020. 
R. A. Ferrer, W. M. Klein, L. E. Zajac, S. R. Land, and B. S. Ling. An affective booster moderates the effect of gain-and loss-framed messages on behavioral intentions for colorectal cancer screening. Journal of behavioral medicine, 35(4):452-461, 2012.

B. Gilbert and J. G. Zivin. Dynamic salience with intermittent billing: Evidence from smart electricity meters. Journal of Economic Behavior \& Organization, 107:176-190, 2014.

R. J. Glass, L. M. Glass, W. E. Beyeler, and H. J. Min. Targeted social distancing designs for pandemic influenza. Emerging infectious diseases, 12(11):1671, 2006.

A. Gollwitzer, C. Martel, J. Marshall, J. M. Höhs, and J. A. Bargh. Connecting self-reported social distancing to real-world behavior at the individual and us state level. 2020.

J. K. Goodman, C. E. Cryder, and A. Cheema. Data collection in a flat world: The strengths and weaknesses of mechanical turk samples. Journal of Behavioral Decision Making, 26(3): 213-224, 2013.

P. Haggard. Human volition: towards a neuroscience of will. Nature Reviews Neuroscience, 9 (12):934-946, 2008.

J. C. Hershey, D. A. Asch, T. Thumasathit, J. Meszaros, and V. V. Waters. The roles of altruism, free riding, and bandwagoning in vaccination decisions. Organizational behavior and human decision processes, 59(2):177-187, 1994.

S. Huck and I. Rasul. Transactions costs in charitable giving: evidence from two field experiments. The BE Journal of Economic Analysis \& Policy, 10(1), 2010.

J. Jordan, E. Yoeli, and D. Rand. Don't get it or don't spread it? comparing self-interested versus prosocially framed covid-19 prevention messaging. 2020.

D. Kahneman and A. Tversky. Prospect theory: An analysis of decision under risk. In Handbook of the fundamentals of financial decision making: Part I, pages 99-127. World Scientific, 2013.

E. J. Kothe, K. Sainsbury, L. Smith, and B. A. Mullan. Explaining the intention-behaviour gap in gluten-free diet adherence: The moderating roles of habit and perceived behavioural control. Journal of health psychology, 20(5):580-591, 2015. 
A. S. Kristal and A. V. Whillans. What we can learn from five naturalistic field experiments that failed to shift commuter behaviour. Nature Human Behaviour, 4(2):169-176, 2020.

M. Li, E. G. Taylor, K. E. Atkins, G. B. Chapman, and A. P. Galvani. Stimulating influenza vaccination via prosocial motives. PloS one, 11(7):e0159780, 2016.

P. D. Lunn, S. Timmons, M. Barjaková, C. A. Belton, H. Julienne, and C. Lavin. Motivating social distancing during the covid-19 pandemic: An online experiment. 2020.

H. Markel, A. Stern, and M. Cetron. Nonpharmaceutical interventions implemented by us cities during the 1918-1919 influenza pandemic. International Journal of Infectious Diseases, 12:e432, 2008.

K. L. Milkman, J. Beshears, J. J. Choi, D. Laibson, and B. C. Madrian. Using implementation intentions prompts to enhance influenza vaccination rates. Proceedings of the National Academy of Sciences, 108(26):10415-10420, 2011.

K. L. Milkman, J. Beshears, J. J. Choi, D. Laibson, and B. C. Madrian. Planning prompts as a means of increasing preventive screening rates. Preventive Medicine, 56(1):92-93, 2013.

N. Montinari and M. Rancan. Social preferences under risk: the role of social distance. Technical report, Jena Economic Research Papers, 2013.

A. Muscillo and P. Pin. Covid19: unless one gets everyone to act, policies may be ineffective or even backfire. arXiv preprint arXiv:2003.14239, 2020.

S. R. Porter, M. E. Whitcomb, and W. H. Weitzer. Multiple surveys of students and survey fatigue. New directions for institutional research, 2004(121):63-73, 2004.

R. E. Rhodes and G.-J. de Bruijn. How big is the physical activity intention-behaviour gap? a meta-analysis using the action control framework. British journal of health psychology, 18 (2):296-309, 2013.

A. J. Rothman, S. C. Martino, B. T. Bedell, J. B. Detweiler, and P. Salovey. The systematic influence of gain-and loss-framed messages on interest in and use of different types of health behavior. Personality and Social Psychology Bulletin, 25(11):1355-1369, 1999. 
A. Saba, M. Vassallo, and A. Turrini. The role of attitudes, intentions and habit in predicting actual consumption of fat containing foods in italy. European journal of clinical nutrition, 54 (7):540-545, 2000.

A. R. Schwerdtfeger, C. Schmitz, and M. Warken. Using text messages to bridge the intention-behavior gap? a pilot study on the use of text message reminders to increase objectively assessed physical activity in daily life. Frontiers in psychology, 3:270, 2012.

K. G. Shojania, A. Jennings, A. Mayhew, C. R. Ramsay, M. P. Eccles, and J. Grimshaw. The effects of on-screen, point of care computer reminders on processes and outcomes of care. Cochrane Database of Systematic Reviews, (3), 2009.

F. F. Sniehotta, U. Scholz, and R. Schwarzer. Bridging the intention-behaviour gap: Planning, self-efficacy, and action control in the adoption and maintenance of physical exercise. Psychology \& health, 20(2):143-160, 2005.

A. Sonntag and D. J. Zizzo. On reminder effects, drop-outs and dominance: Evidence from an online experiment on charitable giving. PloS one, 10(8):e0134705, 2015.

S. M. Tom, C. R. Fox, C. Trepel, and R. A. Poldrack. The neural basis of loss aversion in decision-making under risk. Science, 315(5811):515-518, 2007.

S. M. Utych and L. Fowler. Age-based messaging strategies for communication about covid19. Journal of Behavioral Public Administration, 3(1), 2020.

J. J. Van Bavel, K. Baicker, P. S. Boggio, V. Capraro, A. Cichocka, M. Cikara, M. J. Crockett, A. J. Crum, K. M. Douglas, J. N. Druckman, et al. Using social and behavioural science to support covid-19 pandemic response. Nature Human Behaviour, pages 1-12, 2020.

K. M. Vekaria, K. M. Brethel-Haurwitz, E. M. Cardinale, S. A. Stoycos, and A. A. Marsh. Social discounting and distance perceptions in costly altruism. Nature Human Behaviour, 1 (5):1-7, 2017.

M. Vervloet, A. J. Linn, J. C. van Weert, D. H. De Bakker, M. L. Bouvy, and L. Van Dijk. The effectiveness of interventions using electronic reminders to improve adherence to chronic 
medication: a systematic review of the literature. Journal of the American Medical Informatics Association, 19(5):696-704, 2012.

J. T. Vietri, M. Li, A. P. Galvani, and G. B. Chapman. Vaccinating to help ourselves and others. Medical Decision Making, 32(3):447-458, 2012. 


\section{Appendices}

\section{A Test of Balance}

In Table 2, we test balance across treatments in the sociodemographic characteristics of respondents provided by Statistics Denmark. For each covariate, we report the difference between its mean in the different treatment groups and the control mean (with standard errors in parentheses). The results show that covariates are balanced across treatment groups.

Table 2: Balance of covariates across treatments

\begin{tabular}{|c|c|c|c|c|c|c|c|c|}
\hline \multirow[b]{2}{*}{ Variable } & \multirow{2}{*}{ Categories } & \multicolumn{5}{|c|}{ Treatments } & \multirow{2}{*}{$\begin{array}{l}\text { Control } \\
\text { mean }\end{array}$} & \multirow{2}{*}{$\mathrm{N}$} \\
\hline & & Personal & Family & Others & Country & Generic & & \\
\hline \multirow{4}{*}{ Gender } & \multirow[b]{2}{*}{ M } & 0.039 & 0.013 & -0.019 & 0.022 & 0.032 & 0.423 & \multirow{2}{*}{5,310} \\
\hline & & $(-0.026)$ & $(-0.026)$ & $(-0.026)$ & $(-0.026)$ & $(-0.030)$ & $(-0.021)$ & \\
\hline & \multirow{2}{*}{$\mathrm{F}$} & -0.039 & -0.0132 & 0.0192 & -0.0223 & -0.0324 & 0.577 & \multirow{2}{*}{5,310} \\
\hline & & $(-0.026)$ & $(-0.026)$ & $(-0.026)$ & $(-0.026)$ & $(-0.030)$ & $(-0.021)$ & \\
\hline \multirow{10}{*}{ Age } & \multirow[b]{2}{*}{$18-29$} & 0.00276 & 0.00437 & 0.0132 & 0.0166 & -0.0111 & 0.144 & \multirow[b]{2}{*}{5,310} \\
\hline & & $(-0.018)$ & $(-0.019)$ & $(-0.019)$ & $(-0.019)$ & $(-0.021)$ & $(-0.015)$ & \\
\hline & \multirow[b]{2}{*}{ 30-39 } & 0.00342 & 0.00579 & -0.0067 & -0.0079 & 0.0119 & 0.138 & \multirow[b]{2}{*}{5,310} \\
\hline & & $(-0.018)$ & $(-0.018)$ & $(-0.018)$ & $(-0.018)$ & $(-0.022)$ & $(-0.015)$ & \\
\hline & \multirow[b]{2}{*}{$40-49$} & -0.0168 & -0.017 & -0.0236 & -0.0026 & -0.0253 & 0.205 & \multirow[b]{2}{*}{5,310} \\
\hline & & $(-0.021)$ & $(-0.021)$ & $(-0.021)$ & $(-0.021)$ & $(-0.024)$ & $(-0.017)$ & \\
\hline & \multirow{2}{*}{$50-59$} & -0.0041 & 0.0125 & 0.0108 & 0.00833 & 0.0311 & 0.248 & \multirow[b]{2}{*}{5,310} \\
\hline & & $(-0.023)$ & $(-0.023)$ & $(-0.023)$ & $(-0.023)$ & $(-0.027)$ & $(-0.018)$ & \\
\hline & \multirow{2}{*}{$60-69$} & 0.0147 & -0.0057 & 0.00637 & -0.0144 & -0.0066 & 0.264 & \multirow{2}{*}{5,310} \\
\hline & & $(-0.023)$ & $(-0.023)$ & $(-0.023)$ & $(-0.023)$ & $(-0.027)$ & $(-0.019)$ & \\
\hline \multirow{10}{*}{ Region } & \multirow{2}{*}{ Nordjylland } & -0.0164 & -0.024 & -0.0221 & -0.0179 & 0.00645 & 0.121 & \multirow[b]{2}{*}{5,310} \\
\hline & & $(-0.017)$ & $(-0.017)$ & $(-0.017)$ & $(-0.017)$ & $(-0.020)$ & $(-0.014)$ & \\
\hline & & -0.0243 & -0.0349 & -0.0306 & -0.0266 & -0.0167 & 0.261 & \\
\hline & Midtjylland & $(-0.023)$ & $(-0.023)$ & $(-0.023)$ & $(-0.023)$ & $(-0.027)$ & $(-0.019)$ & 5,310 \\
\hline & & 0.00812 & $0.0523^{* *}$ & 0.0206 & 0.0146 & 0.0185 & 0.192 & \\
\hline & Syddanmark & $(-0.021)$ & $(-0.022)$ & $(-0.021)$ & $(-0.021)$ & $(-0.025)$ & $(-0.017)$ & 5,310 \\
\hline & & 0.0217 & 0.00986 & 0.0336 & 0.0133 & -0.04 & 0.308 & \\
\hline & Hovedstaden & $(-0.024)$ & $(-0.025)$ & $(-0.024)$ & $(-0.024)$ & $(-0.028)$ & $(-0.020)$ & 5,310 \\
\hline & Sĩ̃ Šlland & 0.0109 & -0.0033 & -0.0014 & 0.0166 & 0.0317 & 0.119 & 52310 \\
\hline & & $(-0.017)$ & $(-0.017)$ & $(-0.017)$ & $(-0.017)$ & $(-0.021)$ & $(-0.014)$ & 5,310 \\
\hline & 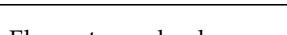 & -0.0112 & $-0.0349^{*}$ & -0.0057 & 0.00717 & 0.00461 & 0.167 & \\
\hline & Elementary school & $(-0.019)$ & $(-0.019)$ & $(-0.019)$ & $(-0.020)$ & $(-0.023)$ & $(-0.016)$ & 5,310 \\
\hline & & 0.00224 & 0.00952 & 0.0186 & 0.00797 & 0.0432 & 0.388 & \\
\hline 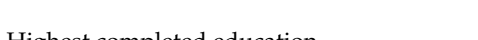 & Youth Education & $(-0.026)$ & $(-0.026)$ & $(-0.025)$ & $(-0.026)$ & $(-0.030)$ & $(-0.021)$ & 5,310 \\
\hline Highest completed education & & -0.0056 & 0.0202 & -0.0153 & 0.0205 & -0.0331 & 0.273 & \\
\hline & Short + Medium Long Ex. & $(-0.023)$ & $(-0.024)$ & $(-0.023)$ & $(-0.024)$ & $(-0.027)$ & $(-0.019)$ & 5,310 \\
\hline & 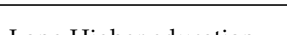 & 0.0146 & 0.00526 & 0.00242 & $-0.0356^{*}$ & -0.0146 & 0.171 & $=010$ \\
\hline & Long Higher education & $(-0.020)$ & $(-0.020)$ & $(-0.020)$ & $(-0.019)$ & $(-0.023)$ & $(-0.016)$ & 5,310 \\
\hline & 5150 & -0.0175 & -0.0074 & -0.0003 & -0.0045 & -0.0199 & 0.155 & 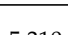 \\
\hline & $<150$ & $(-0.019)$ & $(-0.019)$ & $(-0.019)$ & $(-0.019)$ & $(-0.022)$ & $(-0.015)$ & 5,310 \\
\hline & & -0.0293 & -0.0255 & -0.0081 & 0.00487 & -0.0093 & 0.255 & \\
\hline 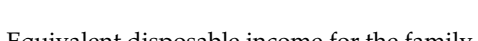 & $150-250$ & $(-0.023)$ & $(-0.023)$ & $(-0.023)$ & $(-0.023)$ & $(-0.027)$ & $(-0.019)$ & 5,310 \\
\hline Equivalent disposable income for the family & 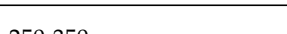 & 0.0265 & 0.0311 & 0.00189 & 0.0046 & $0.0723^{* *}$ & 0.273 & -010 \\
\hline & $250-350$ & $(-0.024)$ & $(-0.024)$ & $(-0.023)$ & $(-0.023)$ & $(-0.028)$ & $(-0.019)$ & 5,310 \\
\hline & & 0.0203 & 0.00186 & 0.00656 & -0.005 & -0.0431 & 0.317 & \\
\hline & $>350$ & $(-0.025)$ & $(-0.025)$ & $(-0.024)$ & $(-0.024)$ & $(-0.028)$ & $(-0.020)$ & 5,310 \\
\hline
\end{tabular}

Notes: For each covariate we test the difference in means between the control group and the treatment groups. Each cell shows the difference with standard errors in parentheses. Confidence: ${ }^{* * *} \mathrm{p}<0.01,{ }^{* *} \mathrm{p}<0.05,{ }^{*} \mathrm{p}<0.10$. 


\section{B Treatments}

This section shows the reminders as they appeared to respondents. For each reminder, we indicate the main focus of the framing ("you", "family", "others", "country") and whether the message was framed in terms of the risks from not complying ("loss") or the benefits from complying ("gain") with the recommendation to stay home.

Table 3: Treatments

\begin{tabular}{|c|c|c|}
\hline $\begin{array}{c}\text { FRAME } \\
\text { (Consequences for...) }\end{array}$ & $\begin{array}{l}\text { DOMAIN } \\
\text { (Loss Gain) }\end{array}$ & MESSAGE \\
\hline \multicolumn{2}{|l|}{ CONTROL GROUP } & NO REMINDER \\
\hline \multirow{2}{*}{ PERSONAL } & Loss & $\begin{array}{l}\text { IF YOU GO OUTSIDE AND } \\
\text { BECOME INFECTED, } \\
\text { YOU MAY GET } \\
\text { VERY SSRIIUUS } \\
\text { RESPIRATORY PROBLEMS } \\
\text { STAY HOME AS } \\
\text { MUCH AS } \\
\text { POSSIBLE }\end{array}$ \\
\hline & Gain & 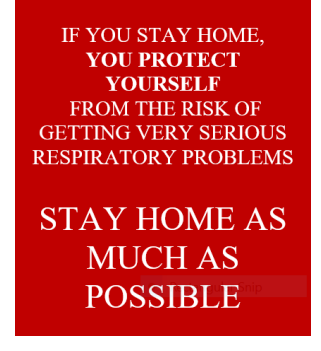 \\
\hline \multirow{2}{*}{ FAMILY } & Loss & 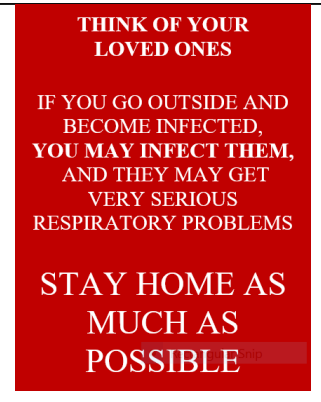 \\
\hline & Gain & 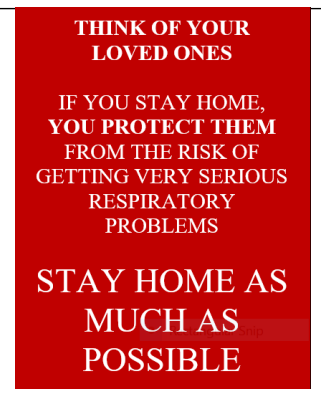 \\
\hline
\end{tabular}




\begin{tabular}{|c|c|c|}
\hline \multirow{2}{*}{ OTHERS } & Loss & $\begin{array}{c}\text { IF YOU GO OUTSIDE AND } \\
\text { BECOME INFECTED, } \\
\text { YOU MAY INFECT } \\
\text { OTHERS, } \\
\text { WHO MAY GET VERY } \\
\text { SERIOUS RESPIRATORY } \\
\text { PROBLEMS } \\
\text { STAY HOME AS } \\
\text { MUCH AS } \\
\text { POSSIBLE }\end{array}$ \\
\hline & Gain & $\begin{array}{c}\text { IF YOU STAY HOME, } \\
\text { YOU PROTECT OTHERS } \\
\text { FROM THE RISK OF } \\
\text { GETTING VERY SERIOUS } \\
\text { RESPIRATORY PROBLEMS } \\
\text { STAY HOME AS } \\
\text { MUCH AS } \\
\text { POSSIBLE }\end{array}$ \\
\hline \multirow{2}{*}{ COUNTRY } & Loss & $\begin{array}{l}\text { IF YOU GO OUTSIDE AND } \\
\text { BECOME INECTED, } \\
\text { YOU MAY CONTRIBUTE } \\
\text { TO AN OVERLOAING } \\
\text { OF THE DANSH HEALTH } \\
\text { CARE SYSTEM } \\
\text { STAY HOME AS } \\
\text { MUCH AS } \\
\text { POSSIBLE }\end{array}$ \\
\hline & Gain & $\begin{array}{l}\text { IF YOU STAY HOME, } \\
\text { YOU REDUCE THE RISK } \\
\text { OF AN OVERLOADING OF } \\
\text { THE DANSII HEALTH } \\
\text { CARE SYSTEM } \\
\\
\text { STAY HOME AS } \\
\text { MUCH AS } \\
\text { POSSIBLE }\end{array}$ \\
\hline & & $\begin{array}{l}\text { STAY HOME AS } \\
\text { MUCH AS } \\
\text { POSSIBLE }\end{array}$ \\
\hline \multicolumn{2}{|c|}{ GENERIC WARNING } & \\
\hline
\end{tabular}




\section{Questionnaires}

This section reports the questions that form part of the two questionnaires we administered. Respondents completed the first questionnaire immediately after reading the reminder. They received and completed the second questionnaire in the following days (no earlier than two days after completing the first questionnaire to prevent inconsistent answers).

Table 4 reports the English translation of all the questions in the first questionnaire. Table 5 reports the English translation of all the questions in the second questionnaire.

\section{Table 4: First questionnaire}

\begin{tabular}{|c|c|c|}
\hline & QUESTION & OPTIONS \\
\hline Q1 & On a scale from 1 to 5 , how worried do you feel at the moment? & $1-5$ \\
\hline Q2 & On a scale from 1 to 5 , how sad do you feel at the moment? & $1-5$ \\
\hline Q3 & How do you think your health is overall? & $\begin{array}{l}\text { - Excellent } \\
\text { - Very good } \\
\text { - Good } \\
\text { - Not very good } \\
\text { - Bad } \\
\text { - Do not know }\end{array}$ \\
\hline Q4 & $\begin{array}{l}\text { For how long do you think you will go out of your house tomorrow? } \\
\text { Please give your answer in minutes and/ or hours } \\
\text { (If you are spending time in your own garden, it is seen as staying home, so you should not include this time in your answer) }\end{array}$ & Hours and Minutes \\
\hline Q5 & $\begin{array}{l}\text { What is the maximum distance from home you are going to reach tomorrow? } \\
\text { Please give your answer in meters and/or kilometers } \\
\text { (If you are spending time in your own garden, it is seen as staying and you should answer " } 0 \text { ") }\end{array}$ & Kilometers and Meters \\
\hline Q6 & $\begin{array}{l}\text { For how long do you think, on average, other people in Denmark will go out tomorrow, on average? } \\
\text { Please give your answer in minutes and/ or hours }\end{array}$ & Hours and Minutes \\
\hline Q8 & To what extent do you trust the Danish government to take care of the citizens of the country in connection with the Corona situation? & $\begin{array}{l}\text { - Strongly distrust } \\
\text { - Somewhat distrust } \\
\text { - Neither trust not distrust } \\
\text { - Somewhat trust } \\
\text { - Strongly trust } \\
\text { - Refusing to answer } \\
\text { - Do not know }\end{array}$ \\
\hline
\end{tabular}




\section{Table 5: Follow-up questionnaire}

\begin{tabular}{|c|c|c|}
\hline & QUESTION & OPTIONS \\
\hline Q1 & On a scale from 1 to 5 , where 1 means very little and 5 means very much, how angry do you feel at the moment? & $1-5$ \\
\hline Q2 & On a scale from 1 to 5 , where 1 means very little and 5 means very much, how worried do you feel at the moment? & $1-5$ \\
\hline Q3 & On a scale from 1 to 5 , where 1 means very little and 5 means very much, how sad do you feel at the moment? & $1-5$ \\
\hline Q4 & $\begin{array}{l}\text { For how long did you leave your home yesterday? } \\
\text { (If you are spending time in your own garden, it is seen as staying home, so you should not include this time in your answer) }\end{array}$ & Hours and Minutes \\
\hline Q5 & What was the maximum distance from home you reached yesterday? & Kilometers and Meters \\
\hline Q6 & What were the reasons for you to leave your home yesterday (check all that apply)? & $\begin{array}{l}\text { - Work } \\
\text { - Purchase } \\
\text { - Physical activity (e.g., walking, running, cycling) } \\
\text { - Medical treatment (e.g., in hospital or at own doctor) } \\
\text { - Drugstore } \\
\text { - Visiting / caring for relatives } \\
\text { - Ventilate a pet } \\
\text { - Meet with friends or family } \\
\text { - Other: }\end{array}$ \\
\hline Q7 & $\begin{array}{l}\text { Did someone else who lives with you go out yesterday? } \\
\text { (If the individual was only in his/her own garden, it is seen as staying hope and you are asked to answer "no") }\end{array}$ & $\begin{array}{l}\text { - Yes } \\
\text { - No } \\
\text { - Refusing to answer } \\
\text { - Do not know }\end{array}$ \\
\hline Q8 & How much do you trust the Danish government to take care of its citizens? & $\begin{array}{l}\text { - Strongly distrust } \\
\text { - Somewhat distrust } \\
\text { - Neither trust not distrust } \\
\text { - Somewhat trust } \\
\text { - Strongly trust } \\
\text { - Refusing to answer } \\
\text { - Do not know }\end{array}$ \\
\hline Q9 & On a scale from 0-100 how important do you think it is that everyone stays at home in Denmark? & $0-100$ \\
\hline Q10 & On a scale from 0 - 100 how important do you think others believe it is to stay at home in Denmark? & $0-100$ \\
\hline Q11 & How effective do you think the social distancing measures are in slowing down the spread of the coronavirus? & $\begin{array}{l}\text { - Very effective } \\
\text { - Effective } \\
\text { - Neither effective nor ineffective } \\
\text { - Not effective } \\
\text { - Not effective at all } \\
\text { - Do not know }\end{array}$ \\
\hline Q12 & Which of the following consequences of the epidemic are you most concerned about? & $\begin{array}{l}\text { - Health system overload } \\
\text { - Economic consequences of the shutdown for Denmark } \\
\text { - Financial consequences of the shutdown for my family } \\
\text { - The effect of isolation on my well-being } \\
\text { - The impact on my social life and lifestyle } \\
\text { - Other things }\end{array}$ \\
\hline Q13 & $\begin{array}{l}\text { How strongly do you agree with the following statement? } \\
\text { "The healthcare system will be overloaded by the COVID19 epidemic". }\end{array}$ & $\begin{array}{l}\text { - Strongly agree } \\
\text { - Agree } \\
\text { - Neither agree or disagree } \\
\text { - Disagree } \\
\text { - Strongly disagree } \\
\text { - Refusing to answer } \\
\text { - Do not know }\end{array}$ \\
\hline Q14 & How many people in Denmark do you think will be infected (tested positive) with Coronavirus in a month? & $0-\ldots$ \\
\hline
\end{tabular}




\section{Table of Main Results}

This section reports the full set of regression results discussed in the article (see Figure 2).

Table 6: Effect of treatments and sub-treatments on staying home (intention vs. action)

\begin{tabular}{|c|c|c|c|c|}
\hline VARIABLES & $\begin{array}{c}(1) \\
\text { Intention }\end{array}$ & $\begin{array}{c}(2) \\
\text { Action } \\
\end{array}$ & $\begin{array}{c}(3) \\
\text { Intention }\end{array}$ & $\begin{array}{c}(4) \\
\text { Action }\end{array}$ \\
\hline You & $\begin{array}{c}0.044^{* * *} \\
(0.016)\end{array}$ & $\begin{array}{c}0.0288 \\
(0.0188)\end{array}$ & & \\
\hline Family & $\begin{array}{c}0.044^{* * *} \\
(0.016)\end{array}$ & $\begin{array}{c}0.0217 \\
(0.0189)\end{array}$ & & \\
\hline Others & $\begin{array}{c}0.012 \\
(0.016)\end{array}$ & $\begin{array}{c}0.0135 \\
(0.0185)\end{array}$ & & \\
\hline Country & $\begin{array}{c}0.025 \\
(0.016)\end{array}$ & $\begin{array}{c}0.0298 \\
(0.0188)\end{array}$ & & \\
\hline You loss & & & $\begin{array}{l}0.0449^{* *} \\
(0.0196)\end{array}$ & $\begin{array}{c}0.0273 \\
(0.0223)\end{array}$ \\
\hline You gain & & & $\begin{array}{l}0.0432^{* *} \\
(0.0193)\end{array}$ & $\begin{array}{c}0.0302 \\
(0.0221)\end{array}$ \\
\hline Family loss & & & $\begin{array}{l}0.0471^{* *} \\
(0.0198)\end{array}$ & $\begin{array}{c}0.0251 \\
(0.0223)\end{array}$ \\
\hline Family gain & & & $\begin{array}{l}0.0398^{* *} \\
(0.0197)\end{array}$ & $\begin{array}{c}0.0183 \\
(0.0223)\end{array}$ \\
\hline Others loss & & & $\begin{array}{l}0.00421 \\
(0.0181)\end{array}$ & $\begin{array}{c}-0.000453 \\
(0.0214)\end{array}$ \\
\hline Others gain & & & $\begin{array}{c}0.0181 \\
(0.0181)\end{array}$ & $\begin{array}{c}0.0260 \\
(0.0216)\end{array}$ \\
\hline Country loss & & & $\begin{array}{c}0.0270 \\
(0.0185)\end{array}$ & $\begin{array}{c}0.0171 \\
(0.0215)\end{array}$ \\
\hline Country gain & & & $\begin{array}{c}0.0237 \\
(0.0189)\end{array}$ & $\begin{array}{l}0.0436^{*} \\
(0.0227)\end{array}$ \\
\hline Generic & $\begin{array}{c}0.025 \\
(0.019)\end{array}$ & $\begin{array}{c}0.0322 \\
(0.0223)\end{array}$ & $\begin{array}{c}0.0249 \\
(0.0190)\end{array}$ & $\begin{array}{c}0.0322 \\
(0.0224)\end{array}$ \\
\hline Controls & Yes & Yes & Yes & Yes \\
\hline Observations & 5,310 & 5,310 & 5,310 & 5,310 \\
\hline
\end{tabular}

Notes: The table shows the effect of receiving each reminder on the probability of staying home (relative to receiving no reminder). Control mean (intentions) $=0.0953$; Control mean (actions) $=0.1457$. Intentions refer to the day after the first interview, actions refer to the day before the follow-up interview. Respondents who referred to a weekday in the first interview and to a weekend day in the follow-up interview (and vice-versa) are dropped from the sample to avoid inconsistencies. The resulting sample size is $N=5,310$. Controls include the following balancing covariates (used at the randomisation stage): gender, age, region, education, and household disposable income per capita. Robust standard errors in parentheses. Confidence: ${ }^{* *} \mathrm{p}<0.01$, $^{* *}$ $\mathrm{p}<0.05,{ }^{*} \mathrm{p}<0.10$. 


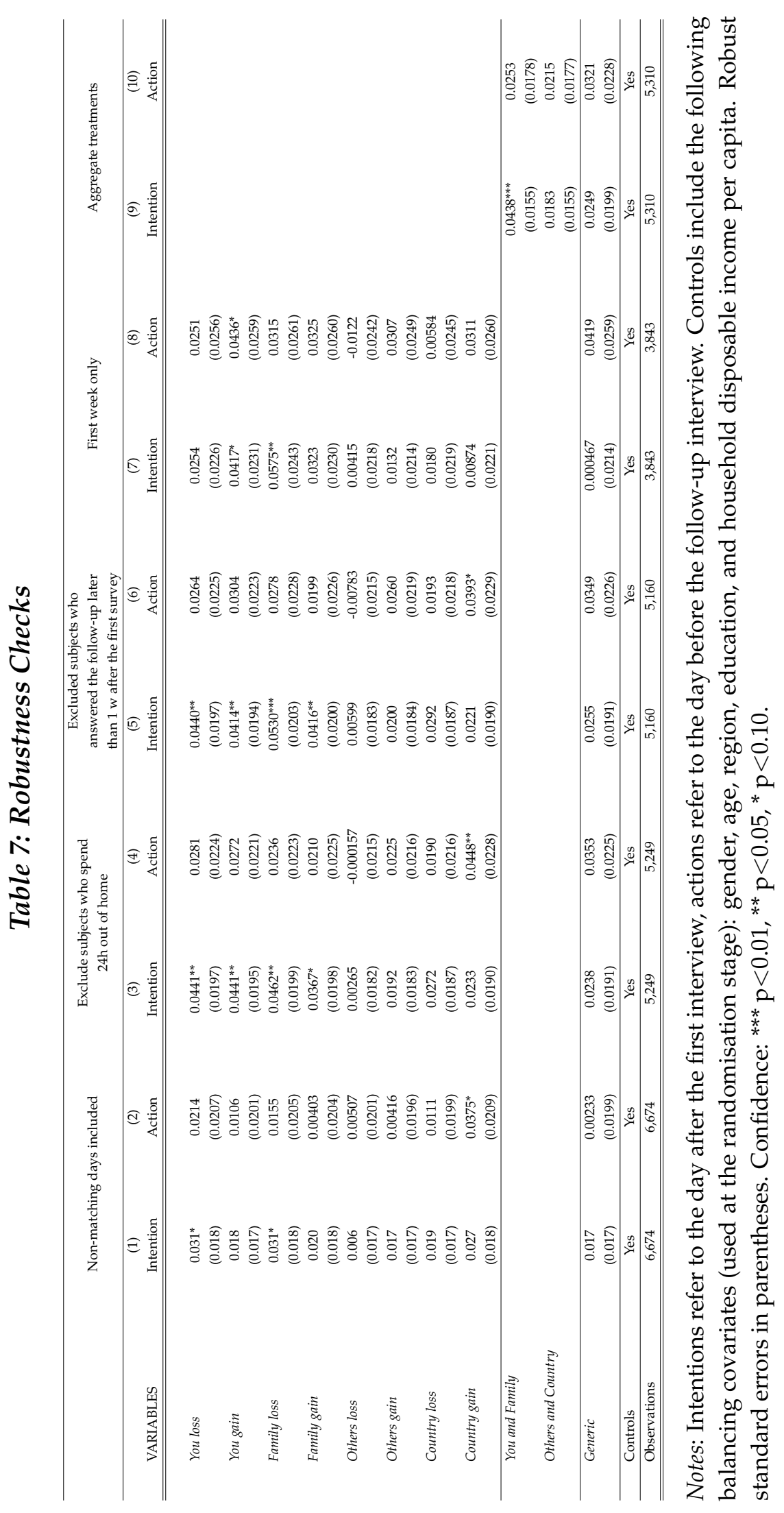




\section{F Analysis of Heterogeneous Effects}

Table 8: Heterogeneous effects by health status

\begin{tabular}{lcccc}
\hline & \multicolumn{2}{c}{ Good Health } & \multicolumn{2}{c}{ Bad Health } \\
\hline \multirow{2}{*}{ VARIABLES } & $(1)$ & $(2)$ & $(3)$ & $(4)$ \\
Intention & Action & Intention & Action \\
\hline \hline \multirow{2}{*}{ You loss } & $0.033^{*}$ & 0.0131 & $0.157^{*}$ & $0.161^{*}$ \\
You gain & $(0.020)$ & $(0.0227)$ & $(0.0804)$ & $(0.0877)$ \\
& $0.044^{* *}$ & 0.0270 & 0.0410 & 0.0557 \\
Family loss & $(0.020)$ & $(0.0229)$ & $(0.0666)$ & $(0.0762)$ \\
& $0.034^{*}$ & 0.00574 & $0.156^{* *}$ & $0.174^{* *}$ \\
Family gain & $(0.020)$ & $(0.0226)$ & $(0.0742)$ & $(0.0821)$ \\
& $0.039^{*}$ & 0.0158 & 0.0490 & 0.0386 \\
Others loss & $(0.020)$ & $(0.0232)$ & $(0.0689)$ & $(0.0775)$ \\
& -0.005 & -0.0154 & 0.0856 & 0.124 \\
Others gain & $(0.018)$ & $(0.0217)$ & $(0.0704)$ & $(0.0810)$ \\
& 0.003 & 0.00900 & $0.129^{*}$ & $0.149^{*}$ \\
Country loss & $(0.018)$ & $(0.0220)$ & $(0.0672)$ & $(0.0763)$ \\
& 0.012 & 0.00916 & $0.113^{*}$ & 0.0541 \\
Country gain & $(0.019)$ & $(0.0223)$ & $(0.0668)$ & $(0.0714)$ \\
& 0.016 & 0.0302 & 0.0785 & $0.144^{*}$ \\
Generic & $(0.019)$ & $(0.0234)$ & $(0.0693)$ & $(0.0800)$ \\
& 0.017 & 0.0230 & 0.0747 & 0.0922 \\
Controls & $(0.019)$ & $(0.0231)$ & $(0.0683)$ & $(0.0755)$ \\
\hline Observations & Yes & Yes & Yes & Yes \\
\hline \hline
\end{tabular}

Notes: The table shows the effect of receiving each reminder on the probability of staying home (relative to receiving no reminder). Control mean - Good Health (intentions) $=0.089$; Control mean - Good Health (actions) = 0.138; Control mean - Bad Health (intentions) = 0.14; Control mean - Bad Health (actions) = 0.2. Respondents classify their health status on a 5-point scale. The lowest two values are considered bad health conditions for the purpose of this analysis (focusing exclusively on those with the lowest value would leave us with little statistical power). Health information missing for 3 respondents. Controls include the following balancing covariates (used at the randomisation stage): gender, age, region, education, and household disposable income per capita. Robust standard errors in parentheses. Confidence: ${ }^{* *} \mathrm{p}<0.01,{ }^{* *} \mathrm{p}<0.05,{ }^{*} \mathrm{p}<0.10$. 


\section{G Timeline and Mobility Trends}

In this section, we first report the timeline of the most salient events that occurred during the most critical period of the first pandemic wave in Denmark, up to the end of our study period (Figure 4).

Figure 4: Timeline of relevant events related to the COVID-19 pandemic in Denmark.

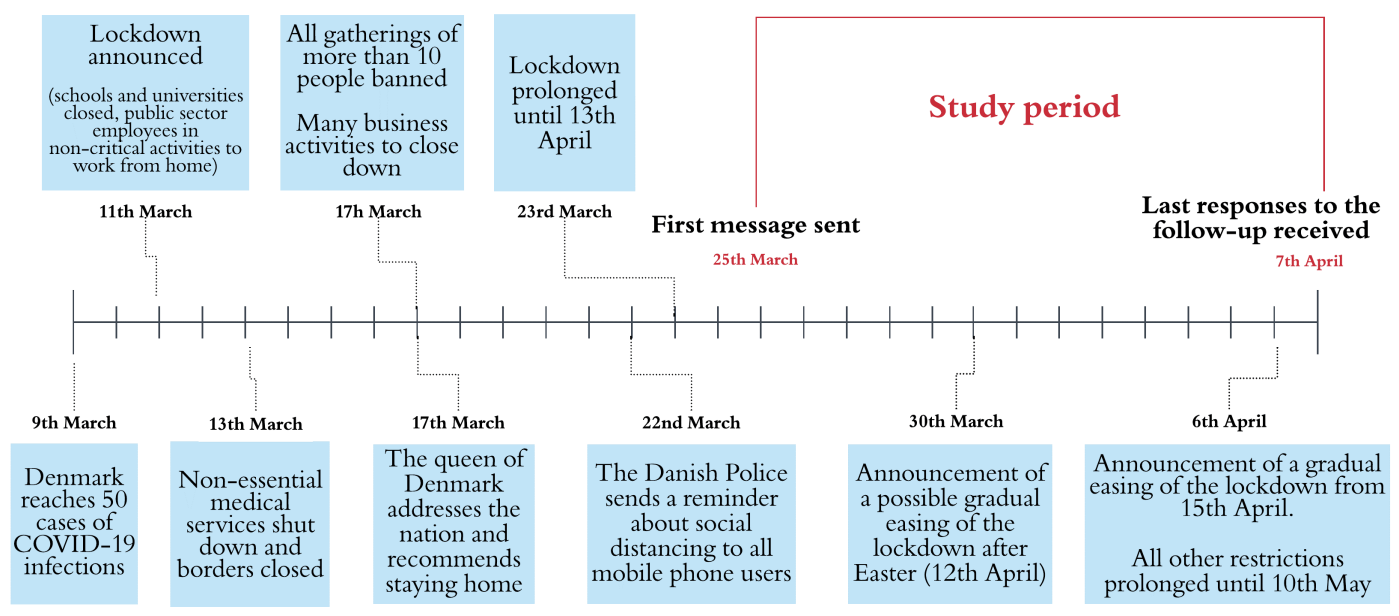

Notes: The figure shows that our intervention took place at a critical moment during the first wave of the pandemic, when maximum attention was placed on social distancing. 
Next, we show that our data on respondents' mobility closely tracks a widely used measure of mobility based on Apple Inc.'s data from mobile-phone users in Denmark (Figure $5)$.

Figure 5: Mobility trends in Demark based on mobile data vs our survey.

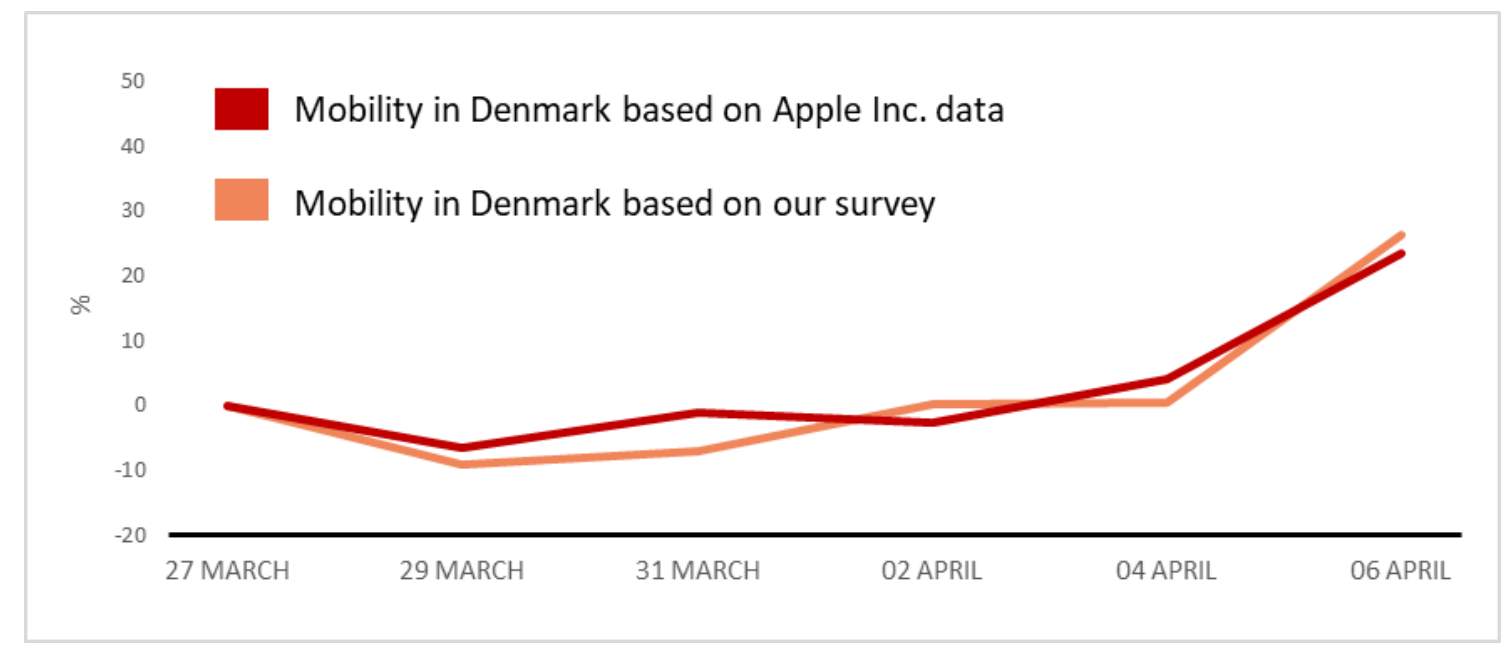

Notes: The figure shows data on how much people travel in Denmark over the period analysed. It compares data from a question on the distance travelled by the respondents in our survey with data from Apple Inc. obtained from routing requests made to Apple web mapping service (Link). For comparability, we plot percentage changes relative to the first date in the period. We exclude extreme values (top $1 \%$ largest distances) and individuals who travelled $<3 \mathrm{~km}$, since the respondents who are most likely to use a web mapping service (and to be comparable to those submitting routing requests to Apple) are the ones traveling outside their own neighborhood. If we relax this restriction, the results are similar, albeit less precise. 


\section{H Attrition}

In this section, we test whether the probability that a respondent drops out of the sample between the first survey and the follow-up survey correlates with assignment to treatment. The raw data in Table 9 show that attrition is strongly balanced across treatment groups.

\section{Table 9: Number of respondents and attrition rate}

\begin{tabular}{ccccc} 
GROUP & DOMAIN & $\begin{array}{c}\text { Completed } \\
\text { first survey }\end{array}$ & $\begin{array}{c}\text { Completed } \\
\text { follow-up survey }\end{array}$ & $\begin{array}{c}\text { Attrition } \\
\text { rate }\end{array}$ \\
\hline \hline Group 0 & 1,285 & 692 & $46 \%$ \\
\hline Group 1 & & 1,268 & 674 & $47 \%$ \\
\hline Group 2 & You & 2,472 & 1,311 & $47 \%$ \\
\hline Group 3 & Family & 2,480 & 1,264 & $49 \%$ \\
\hline Group 4 & Others & 2,508 & 1,397 & $44 \%$ \\
\hline Group 5 & Country & 2,560 & 1,343 & $48 \%$ \\
\hline \hline Total & & 12,573 & 6,681 & $47 \%$
\end{tabular}

As a formal test, we regress the probability of dropping out of the sample on being in each of the treatment groups and we find no relationship (Table 10). When we run the same analysis for the sub-treatments, we reach the same conclusion (only the sub-treatment "Others" in the gain domain is associated with a lower probability of dropping out of the sample, but the result is only significant at the $10 \%$ level). 
Table 10: Effect of the treatments on the attrition rate

\begin{tabular}{lc}
\hline REMINDERS & Attrition \\
\hline \hline Generic & 0.005 \\
& $(0.019)$ \\
You & 0.008 \\
& $(0.017)$ \\
Family & 0.027 \\
& $(0.017)$ \\
Others & -0.019 \\
& $(0.017)$ \\
Country & 0.011 \\
& $(0.017)$ \\
Constant & 0.450 \\
& $(0.304)$ \\
\hline Controls & Yes \\
\hline Observations & 12,573 \\
\hline
\end{tabular}

Notes: Attrition between the first and the second survey. Controls include the following balancing covariates (used at the randomisation stage): gender, age, region, education and household income. Robust standard errors in parentheses. Confidence: ${ }^{* * *} \mathrm{p}<0.01,{ }^{* *} \mathrm{p}<0.05,{ }^{*} \mathrm{p}<0.1$. 